\title{
Canadian parent perceptions of oral food challenges: A qualitative analysis
}

Natasha Correa ${ }^{1}$, Jennifer Protudjer ${ }^{2}$, Elaine $\mathrm{Hsu}^{3}$, Lianne Soller ${ }^{3}$, Edmond Chan ${ }^{3}$, Harold L. Kim ${ }^{1}$, and Samira Jeimy ${ }^{1}$

${ }^{1}$ Western University

${ }^{2}$ University of Manitoba

${ }^{3}$ The University of British Columbia

July 6, 2021

\section{Hosted file}

Main text file.docx available at https://authorea.com/users/424178/articles/529322-canadianparent-perceptions-of-oral-food-challenges-a-qualitative-analysis 
Solutions to barriers

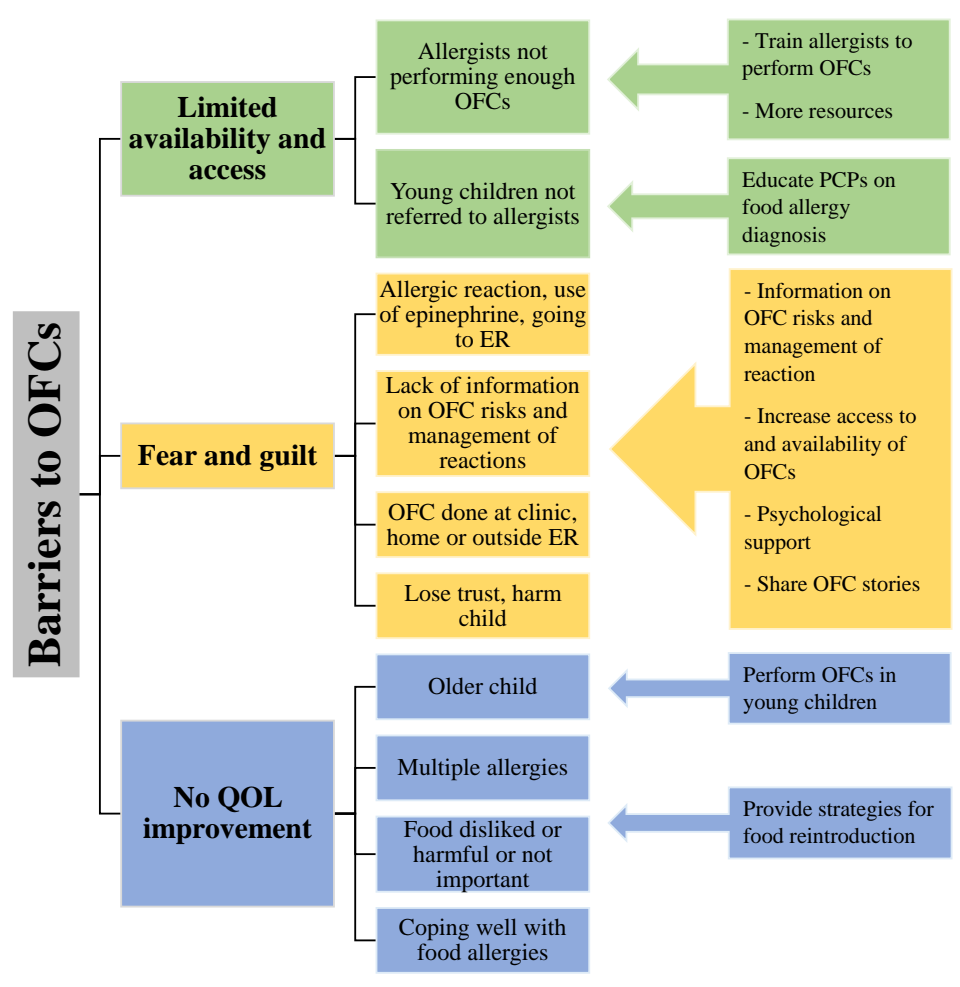

